\title{
What is the Value of Tissue Chips?
}

\section{Eric Gottwald}

Karlsruhe Institute of Technology (KIT), Institute for Biological Interfaces-1, Hermannn-von-Helmholtz-Platz, Eggenstein-Leopoldshafen, Germany

An increasing pressure, exerted on the one hand through ever increasing costs for the development of new drugs, and on the other hand by the public, that stipulates animal free research, has led to the development of more and more sophisticated in vitro test systems. Among them, special attention has to be turned on tissue chips since they have got an enormous potential with regard to being developed to true organ-on-chip or even mouse-on-chip-systems due to the organotypic behaviour of the cells, at least to some respects.

The replacement of animal experimentation has been payed great attention to, at the latest since the introduction of the 3R-concept by Russel and Burch [1] and the 4R-principle by Banks [2]. The problems with animal experiments are tackled in different ways, like e.g. computer simulation studies, and micro dosing, but most notably by the development of appropriate in vitro-systems.

The development of in vitro-systems, especially 3D-culture systems on a chip-basis, experiences an increasing interest in the last decade although the remarkable differences between $2 \mathrm{D}$ and $3 \mathrm{D}$ in cellular behaviour have been discovered as early as in the middle of the last century. For example, with the help of tumor spheroids it could be shown that these multicellular aggregates harbor radiation resistant, hypoxic cells that retain their growth potential [3] or that a 3D-configuration is able to restore or maintain the diffentiated status of adult cells such as hepatocytes, cardiac myocytes, chondrocytes, and endocrine pancreatic islet cells [4]. These developments were enabling technologies to study at least partially aspects of whole organ functions. Partially, because of the inherent disadvantages of in vitro-techniques of e.g. not being able to examine whole organism metabolic responses with its associated drug- metabolites that are derived by precursors during the first-pass-effect for instance. However, the development of more complex tissue chips is striving for even more organotypic behavior and is aiming at real organ-chips substituting mother nature's paradigm. One major advantage of those systems could be that they can be equipped with the tissue of interest, which means for drug screening purposes, often times human cells can be used. And even in case the in vitro-model is a simplified one, the information that can be extracted from it, might resemble more closely the human body situation than a whole body experiment in the wrong species. It is known, for example, that the half life of acetyl salicylic acid in humans is about 20-24 hours, whereas those of cats is twice as high and those of horses is just one hour.

This leads to the conclusion that tissue chips, be they simplified models of the whole organ(ism) situation or not are very valuable research tools that are able to reduce costs because of the miniaturization that is linked to a low resource consumption and last but not least to reduce the consumption of experimental animals.

\section{References}

1. Russel WMS, Burch RL (1959) The Principles of Humane Experimental Technique, Methuen, London.

2. Banks R (1995) The $4^{\text {th }} R$ of Research. Contemp Top Lab Anim Sci. 34: 50-51.

3. Sutherland RM, Durand RE (1976) Radiation response of multicell spheroids-an in vitro tumour model. Curr Top Radiat Res Q 11: 87-139.

4. Altmann B, Welle A, Giselbrecht S, Truckenmuller R, Gottwald E (2009) The famous versus the inconvenient - or the dawn and the rise of 3D-culture systems. World J Stem Cells 1: 43-48.
*Corresponding author: Eric Gottwald, Karlsruhe Institute of Technology (KIT), Institute for Biological Interfaces-1, Hermannn-von-Helmholtz-Platz, EggensteinLeopoldshafen, Germany, Tel: + 49-7247-822504; Fax: + 49-7247-825546; E-mail: eric.gottwald@kit.edu

Received December 09, 2010; Accepted December 13, 2011; Published December 15, 2011

Citation: Gottwald E (2011) What is the Value of Tissue Chips? J Biochip Tissue chip 1:e102. doi: 10.4172/2153-0777.1000e102

Copyright: (c) 2011 Gottwald E. This is an open-access article distributed unde the terms of the Creative Commons Attribution License, which permits unrestricted use, distribution, and reproduction in any medium, provided the original author and source are credited. 